\author{
Голочалова И.И., Цуркану В.И.
}

\title{
БУХГАЛТЕРСКИЙ УЧЕТ ВОЗНАГРАЖДЕНИЙ НА ОСНОВЕ АКЦИЙ В ИННОВАЦИОННОЙ ЭКОНОМИКЕ: ТЕОРИЯ И ПРАКТИКА
}

\begin{abstract}
При модели инновационной экономики труд, связанный с использованием интеллектуальных, предпринимательских и организаторских способностей индивидуума, рассматривается как отдельньіи производственный фактор в составе капитала, получивший название человеческий капитал. Этот фактор производства с одной сторонь является деятельностью, требующей вознаграждения в виде оплаты, а с другой - исходя из права собственности индивидуума переданного организачии, частью ее капитала. Следовательно, он носит двойственный характер, в результате чего возникает проблема методологического характера, требующая разрешения в контексте конщепции достоверности финансовой отчетности. В данном исследовании авторы используют концептуальный подход, решая проблему бухгалтерского учета вознаграждений на основе акций, который заключается: в юридическом обосновании признания вознаграждений на основе акций в качестве капитала в рамках экономической трактовки определения их в качестве реинвестированной прибыли и предложении модели бухгалтерского учета данного рода вознаграждений в контексте правил МСФО.
\end{abstract} ключевые слова: вознаграждения на основе акций, человеческий капитал, признание,
реинвестированная прибыль, концепция оценки по справедливой стоимости, методология бухгалтерского учета.

Постановка проблемы. При любой модели экономики определяющими факторами ее развития и роста благосостояния являются капитал и труд. Капитал как многогранная экономическая категория на протяжении длительного времени изучалась признанными школами экономической теории: в рамках одних - выяснялась экономическая суть и содержание капитала, другие - сформировали представление о нем как источнике благосостояния и положили начало теории его стоимости, третьи продолжили развитие научной мысли в части становления концепции оценки размера капитала. Поводом для исследований и дискуссий вокруг понятия «капитал» являлись эволюционные процессы в экономике, которые обычно завершаются сменой одной модели экономического развития на другую (например, переход от модели индустриальной экономики к модели, основанной на инновациях). Труд как другой фактор экономического развития понимался достаточно однозначно и ясно осознанная общепризнанная деятельность человека с целью создания общественных материальных благ, подлежащая оценке и

(C) Ирина Николаевна Голочалова, к.э.н, доцент, Государственный университет Молдовы, г. Кишинев, Р. Молдова, тел.: +373602875373, email: monomah5@ yandex.ru

Виорел Иванович Цуркану, д.э.н, профессор, Молдавская Экономическая Академия, г. Кишинев, Р. Молдова, тел. +37379662011, email: vturcanu@mail.ru вознаграждению. Однако при модели инновационной экономики труд, известный как $\beta$ активность (использование интеллектуальных и предпринимательских способностей индивидуума), рассматривается как отдельный производственный фактор в составе капитала, получивший название человеческий капитал. В контексте двойственного характера этого фактора производства, который с одной стороны является деятельностью, требующей вознаграждения, а с другой - исходя из права собственности индивидуума, частью капитала организации, возникает ряд проблем в системе бухгалтерского учета. Следует отметить, что в экономической литературе рассматриваются различные дискуссионные вопросы, излагаются теоретические взгляды, предлагаются методы оценки вознаграждения за $\beta$-активность, известное в системе бухгалтерского учета как вознаграждение на основе долевых инструментов.

Анализ последних достижений и публикаций. Известными представителями научных школ теории капитала являются А. Смит, Е. Бём-Баверк, Й. Шумпетер, И. Фишер, А. Маршалл, Ч. Шпруг. Исследованию проблемы оценки капитала и распределению его стоимости посвящены работы таких известных западных ученых как: Д. Александер, Л. Мизес [3], Дж. Хикс, Э. Хендриксен и М. ван Бреда [9], Дж. К. ван Хорн, Р. Энтони, а также ученых Украины, России, Молдовы: В. Ковалев, Я. Крупка, М. Пятов [5], Я. Соколов [8], В. Цуркану [11], К. Цыганков и др. Отметим 
также, что вопрос сущности капитала с точки зрения права раскрывается в трудах П. Гарнье, Е. Годэмэ, Р. Саватье [6] и др., что, несомненно, способствовало развитию методологии бухгалтерского учета. Трактовка капитала, образуемого под влиянием $\beta$-активности работников (человеческого капитала) и его оценки, исследуется в публикациях западных ученых, являющихся основоположниками теории человеческого капитала, а также в работах таких исследователей как: М. Добия, В. Катькало, С. Легенчук [12], Р. Нижегородцев и др. Отдельное внимание этой теме уделено и авторами данного исследования [10].

Тем не менее, в системе бухгалтерского учета отсутствуют: концептуальная основа признания вознаграждения за использование человеческого капитала, его единая система оценки, унифицированный механизм бухгалтерского учета операций, связанных с такого рода вознаграждением. Это, в свою очередь, приводит к снижению достоверности финансовой отчетности об участии человеческого капитала в инновационных процессах бизнес-структур и его воздействии на оценку бизнеса в целом. Обозначенная проблема в контексте современной методологии учета требует углубленного рассмотрения.

Формулирование цели статьи. Целью данного исследования является характеристика и анализ экономического воздействия на содержание финансовой отчетности вознаграждения на основе акций, которое будет проведено по следующей схеме:

- юридическое обоснование его признания в качестве капитала;

- трактовка в концепциях менеджмента капитала;

- иллюстрация бухгалтерского учета операций, связанных вознаграждением работников на основе акций в контексте МСФО.

Результаты исследования. 1. Юридическое обоснование признания в качестве капитала вознаграждения на основе акций. В современной системе гражданских правоотношений выдвинут тезис: капитал как один из видов собственности выступает важнейшим объектом правового регулирования и, в соответствии с этим, его сущность проявляется через определение прав собственника и обязательств перед ним. Приведем доказательства обоснованности этого тезиса. Правоотношения собственников - это некоторая система, предусматривающая исключение определенных лиц из числа обладателей прав на ограниченные ресурсы, целью которой является регулирование поведения собственников (экономических субъектов) для получения ими экономического эффекта от использования этих прав. Субъектами правоотношений могут быть как отдельные люди (физические лица), так и абстрактные образования, наделенные свойством юридического лица с помощью юридической техники.

Физическое лицо-правообладатель права собственности (право владения, право пользования, право управления и др.) может на их основе либо авансировать свою деятельность, либо изымать ценности, используя для своих других хозяйственных целей, или направляя их для покрытия личных расходов. В этом случае эти операции не имеют юридического значения, поскольку действия с имуществом касаются только одного субъекта права, который не может быть ни должником, ни кредитором в отношении самого себя, хотя они имеют экономическое значение и подлежат отражению в учете [6, с. 22]. В том случае, когда предприятие, как таковое, не является юридическим лицом, отсутствует и юридическое понимание капитала.

По мере расширения экономических отношений определяющую роль в развитии экономики стали играть предприятия, представляющие собой объединения собственников определенных прав. Поскольку эти объединения (абстрактные лица) отделены от реальных людей-собственников, это привело к изменению статуса права собственника: из категории вещного права оно трансформировалось в обязательственное право. Для того чтобы обязательственное право имело юридическую силу, необходимо, обладание предметом права (имуществом) ценностью и законностью, что подразумевает различные гарантии, устанавливаемые определенными договорами, обеспечивающие исполнение должником его обязанностей. В рамках членства в объединении (товариществе, обществе) каждому его участнику (реальному лицу) такие гарантии предоставляются в виде долей или совокупностью акций, подтверждающие обязательственные права на имущество объединения. Главное в обязательственном праве, что дает основание кредиторам получить имущество от определенных лиц-должников, это: определение экономической ценности имущества, являющегося объектом права; установление, кто в правоотношениях является кредитором, а кто должником [6, с. 45]. Таким образом, применяя юридическую технику, учредители создают юридическое лицо с целью извлечения прибыли от собственного имущества, 
которое

становится

участником

правоотношений, регулируемых обязательственным правом, обладает правом на имущество и способно отвечать имуществом по своим обязательствам. Согласно некоторым договорам происходит объединение не имущества физических лиц, а - капиталов юридических лиц, участники которого интересуются главным образом деятельностью, которая объединяется. В результате устанавливаются правоотношения между их участниками, одни из которых, предоставившие свое имущество для предпринимательской деятельности, становятся кредиторами в суммах, пропорциональных вложенным каждым из них средствам, другие, использующие его должниками перед ними.

Таким образом, на основании учредительного акта (юридического договора) одновременно признаются: права требования кредитора учредителя по осуществленным взносам; права на собственность юридического лица, которая перестает использоваться учредителями. Эти права в отношении собственности образуют капитал юридического лица, как следствие допущения имущественной обособленности, который демонстрирует правоотношения между юридическим лицом и его учредителями (рис.1).

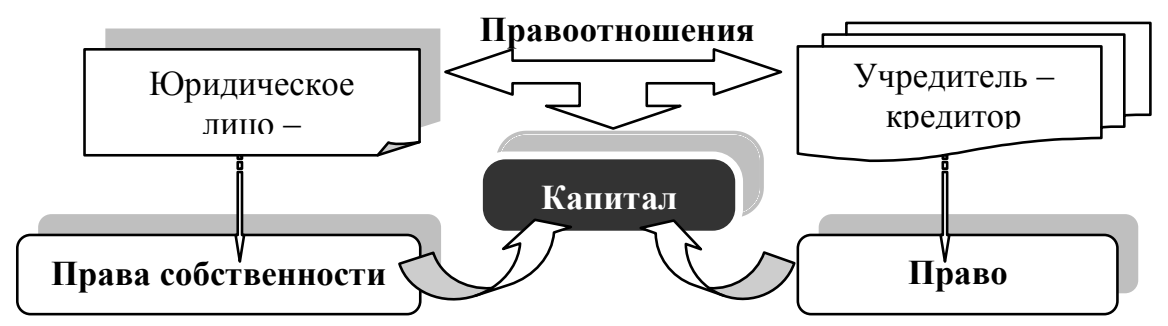

\section{* Авторская разработка}

Рис.1. Место капитала в системе правоотношений *

Приверженцем указанный юридической трактовки капитала является исследователь М. Пятов, который в своей работе приводит следующее определение: “собственные источники средств (имущества) - это потенциальная задолженность перед своими акционерами (собственниками)" [5, с. 75]. Другого мнения придерживается известный немецкий исследователь сущности капитала Л. Мизес, который исключает юридическую трактовку капитала, считая, что это элемент экономического расчета действенный только в той мере, в какой возникает необходимость в данных бухгалтерского учета у бизнеса для представления экономических проблем [3, с. 481-486].

Доля собственников (учредителей, акционеров) в капитале предоставляет не только право требования своей части при распределении капитала, но и право на получение вознаграждения за пользование собственностью (выплаченные дивиденды), а также право на принятие управленческих решений, которое добавляясь к праву требования, увеличивает его экономическую ценность. Становится очевидным, что право собственника гораздо полнее, чем право обычного кредитора.

Итак, созданное юридическое лицо живет своей “самостоятельной жизнью”: приобретает имущество, производит продукцию, получает кредиты и отчуждает принадлежащие ему средства, и в этом процессе у него появляется еще один кредитор - работники, труд которых является вторым производственным фактором. Естественным представляется факт отличия между обязательствами, возникающими из обычного трудового договора, и обязательствами, возникающими из учредительного договора. В первую очередь, собственники отличаются от работников тем, что им принадлежит право на капитал бизнесединицы, и они коллективно на условиях паритетности руководят им, тогда как работники, наоборот, не обладают никакими правополномочиями и находятся в его подчинении. Второе отличие заключается в том, что труд как средство производства направлен на создание ценностей, одна часть которых предназначена для потребления обществом, тогда как другая часть направлена на увеличение капитала бизнес-единицы, поскольку создается при помощи этого средства производства. Как известно, вознаграждением за капитал является распределение чистого прироста капитала, что осуществляется в виде выплаты дивидендов, тогда как вознаграждение работников для юридического лица является расходом, вычитаемым из доходов от потребления ценностей обществом. Следовательно, у работников отсутствует какое-либо право на долю в капитале. Эти отличия имеют юридическое обоснование, поскольку 
обусловлены содержанием соответствующих договоров.

Однако со временем произошли изменения во взаимоотношениях капитала и труда, что особенно ярко проявляется при смене модели индустриальной экономики на модель, основанную на инновациях - продукта человеческого капитала. При инновационной модели развития экономики, условно разделенной на два сектора - «производство материальных благ» и «производство человека», и труд разделен на $\alpha$ - и $\beta$-активность $(\alpha-$ физический труд, $\beta$ - интеллектуальная и организаторская деятельность) [2, с. 112]. Работник проявляя $\beta$-активность создает ценности, известные как неосязаемые ресурсы, которые, способствуя формированию конкурентных преимуществ бизнес-единицы, входят в сферу смежных имущественных прав, как со стороны работника, так и со стороны бизнес-структуры. Таким образом, $\beta$-активность - это проявление человеческого капитала, который становится компонентом совокупного капитала, поскольку обеспечивает его собственнику получение выгод в течение некоторого времени. Рассмотрим подробнее это утверждение.

Итак, если собственником капитала является реальное физическое лицо, то оно, как правило, вносит свой труд организатора - $\beta$-активность, для эффективной деятельности предприятия. Естественно, что его чистая прибыль образуется одновременно его капиталом и его $\beta$ активностью. Обязательства такого собственника перед работниками за $\alpha$-активность ограничиваются заработной платой. Но в условиях деятельности бизнес-единицы, капитал которой принадлежит юридическому лицу, происходят изменения в оплате труда. Юридическое лицо поручает некоторым физическим лицам (менеджерам), обладающими способностями, навыками, знаниями управление бизнес-единицей координировать производственные процессы, оптимизировать использование всех видов ресурсов, обеспечить достижение требуемого финансового эффекта, и в конечном итоге создает стоимость бизнеса. Поскольку $\quad \beta$-активность менеджеров, способствуют приращению капитала, которое, согласно экономической теории, обусловлено его использованием, то становится очевидным вывод: $\beta$-активность собственно и есть проявление капитала. Естественно возникновение вопроса, какого капитала? Капитала, воплощенного в заnace знаний человека, его навыков и мотиваций, при формировании которого требуется отвлечение средств от текущего потребления ради получения дополнительных доходов в будущем, и который получил название «человеческий капитал» [1, с. 58-59].

Вознаграждение работников, де монстрирующих $\beta$-активность (топ-менеджеры, собственники идей, разработчики инноваций), может осуществляться двумя путями: прямым в качестве обязательства по оплате труда, косвенным - в виде признания права на долю собственности в чистых активах организации. Первый путь обычно применяется на тех этапах деятельности бизнес-единицы, когда минимизировано проявление $\beta$-активности или по выбору самого работника. Второй путь заключается в наделении работников правами на долю совокупного капитала бизнес-единицы, что реализуется на базе специальных договоров финансовых инструментов (опционов, варрантов, акций и др.), которые тем самым придают юридический статус собственникам человеческого капитала. Эти вознаграждения получили название вознаграждения на основе акций.

2. Трактовка вознаграждения работников на основе акций в концепциях менеджмента капитала. Как известно, основу менеджмента бизнес-единицы составляет отношение к капиталу как источнику формирующего непрерывный процесс деятельности. Но в условиях персонифицирования собственника финансового капитала (одно лицо) и управляющих собственностью (топ-менеджеры, работники $\beta$-активности) возникла объективная необходимость разделения капитала на: финансовый, образованный за счет вкладов собственников, и человеческий капитал менеджеров, призванных финансовым капиталом с целью его приращения. В контексте разъяснения экономической сущности вознаграждения на основе акций целесообразно рассмотреть концепции менеджмента капитала. Еще раз подчеркнем, что $\beta$-активность работников особенно ярко демонстрируется при инновационной модели экономики.

Первая теории капитала с позиции менеджмента возникла в рамках американской школы теории учета, известная как модель Ч. Шпруга, согласно которой, в общем смысле капитал - это то, что я стою [8, с. 196-200]. Уже установлено, что капитал является комплексным показателем экономических прав собственников, а прибыль - комплексный оценочный показатель эффективности менеджмента этих экономических прав. Расширим трактовку модели Ч. Шпруга и представим ее авторское понимание: если 
финансовый капитал - это что стоят вкладчики (акционеры), то чистая прибыль - это стоимость капитала вкладчиков и то, что стоят менеджеры. Отсюда авторы сделали вывод: поскольку стоимость вкладчиков финансового капитала определяется размером их вложений и подлежит распределению между ними или реинвестированию, следовательно то, что стоят менеджеры, определяется размером их потенциала (или человеческим капиталом) и подлежит распределению между ними или реинвестированию. Важно, что модель Ч. Шпруга считается исходной точкой современной теории бухгалтерского учета. Экономическая трактовка капитала модели Ч. Шпруга получила дальнейшее развитие в интерпретациях персоналистической школы и институалистской школы, общая характеристика которых представлена в табл.1.

Таблица 1

Общая характеристика теорий капитала в контексте эволюции модели Ч. Шпруга*

\begin{tabular}{||c|c|c||}
\hline Критерии & Персоналисты & Институалисты \\
\hline Цель учета & Определение финансового положения & Исчисление финансового результата \\
\hline $\begin{array}{c}\text { Основное } \\
\text { равенство }\end{array}$ & Капитальное: Активы - Обязательства = Капитал & $\begin{array}{c}\text { Балансовое: Активы = } \\
\text { Обязательства + Капитал }\end{array}$ \\
\hline Пассивы & Источники финансирования & Все средства организации \\
\hline Капитал & $\begin{array}{c}\text { Собственный капитал - задолженность } \\
\text { организации перед собственниками }\end{array}$ & $\begin{array}{c}\text { Совокупный - } \\
\text { капитал организации }\end{array}$ \\
\hline Дивиденды & $\begin{array}{c}\text { Уменьшение капитала как выплаты по } \\
\text { обязательственному праву на долю собственности }\end{array}$ & Расходы организации \\
\hline
\end{tabular}

*Авторская разработка на базе [8].

Идеи разработчиков указанных теорий нашли свое отображение в концепциях собственного капитала. Известно несколько таких концепций, которые достаточно полно рассмотрены известным ученым Э. Хендрескеном [9], однако в рамках данного исследования остановимся на тех, которые имеют методологическое значение для раскрытия экономической трактовки вознаграждений на базе обыкновенных акций. К ним относятся концепции собственности и хозяйствующей единицы. В рамках концепции собственности, базирующейся на понимании акции как доли собственности, капитал трактуется как собственный капитал, представляющий собой чистое благосостояние собственника, которое в момент образования равно сумме инвестированных им средств. Поскольку заемный капитал рассматривается как внешний источник финансирования, то и проценты по нему, также как и налог на прибыль, трактуются как расходы, уменьшающие чистую прибыль. Выплаченные дивиденды в процессе распределения чистой прибыли являются изъятием из собственного капитала. Чистая прибыль - это чистый доход, начисляемый только собственникам вложенного капитала и который увеличивает размер капитала. Отсюда и разделение собственного капитала на две категории: инвестированный капитал и нераспределенная прибыль. Эта концепция применяется в системе бухгалтерского учета и отчетности при условии равноценности вкладов каждого из учредителей и непосредственной связи между собственностью и управлением бизнесом.

Вторая концепция - это теория хозяйствующей единицы, основанной на сущности акции как равной части, что следует понимать так: право на свою справедливую долю в его приросте имеет каждый, кто предоставляет средства организации и формирует ее капитал [9, c. 478]. Концептуальными положениями этой теории обозначены следующие: капитал бизнесединицы трактуется как совокупный капитал, включающий собственный и заемный капитал; учредители и вкладчики могут быть не связаны с основной деятельностью существующей бизнесединицы; функционирование этой единицы направлено, прежде всего, на соблюдение интересов всех вкладчиков капитала. Несмотря на то, что вклады держателей акций и кредиторов учитываются отдельно друг от друга, в совокупности они представляют капитал организации [9, с. 482]. Юридически эта концепции воплощена в корпорации. Чистая прибыль с позиции корпорации - это корпоративная прибыль как разница между всеми доходами и расходами корпорации, которая не имеет отношения к чистой прибыли собственников, которая ограничивается пределом или начисленных дивидендов (акционеров), или приростом стоимости инвестиций (инвесторов). Отметим, что существуют и другие концепции, положенные в основу интегрированной отчетности, реализация цели которой возможна в будущем. 
Каждая из рассмотренных концепций указывает на тот факт, что с экономической точки зрения вознаграждения менеджерам на основе долевых инструментов являются реинвестированной прибылью, поскольку:

- подлежат признанию в качестве человеческого капитала;

- не меняют размер собственного капитала на отчетную дату, хотя и формируются за счет его прироста, а поэтому характеризуют процесс алокации суммы по разным элементам собственного капитала;

- не являются изъятием капитала (выплатой дивидендов).

Использование метода вознаграждений на основе долевых инструментов можно рассматривать как проявление выбранной дивидендной политики отдельной бизнес-единицы, наиболее известными из которых: остаточного капитала (теория безотносительности) и текущих дивидендов (традиционный подход) [7, с. 314]. При использовании теории безотносительности распределения дохода дивиденды выплачиваются исходя из суммы, оставшейся после финансирования приемлемых инвестиционных (инновационных) проектов (ИП), и прочих производственных процессов. Как известно любой ИП основываются в первую очередь на идее, принадлежащей собственнику и эффективном менеджменте по его внедрению. Платой за внедрение таких проектов являются вознаграждения на основе акций, формируемые за счет нераспределенной прибыли, что с точки зрения определения размера собственного капитала представляет процесс реинвестирования. Поэтому, в иные годы, годы разработки и внедрения ИП дивиденды по обыкновенным акциям могут вообще не начисляться, а в некоторые, годы реализации инноваций - будут значительны. Этот риск принимают на себя акционеры, владеющие обыкновенными акциями. Традиционный подход в дивидендной политике основан на тезисе: текущие дивиденды предпочтительнее будущих дивидендов. Однако в условиях его применения акционеры сами принимают решение в пользу реинвестирования прибыли и отказываются от текущих дивидендов в условиях выгодного ИП.

3. Иллюстрация бухгалтерского учета операций, связанных с вознаграждением работников на основе акций в контексте МСФО. Известен факт того, что в системе бухгалтерского учета наибольший интерес представляют операции, которые изменяют структуру капитала или имеют отношение к распределению его прироста. Однако применение различных концепций капитала (собственный капитал или капитал), методов оценки стоимости приводит к различным показателям чистой прибыли, что оказывает влияние и на методологию бухгалтерского учета. Следует отметить, что в контексте внедрения интегрированной отчетности и информационных запросов ее пользователей особо важным становится вопрос представления информации о человеческом капитале [12]. В этой ситуации для составителя финансовой отчетности важно четко следовать требованию достоверности, при выполнении которого, на базе профессионального суждения, необходимо ответить на ряд вопросов: кто является носителем прав собственности, кто является получателем чистой прибыли, каким образом оценить распределяемую долю, и какой механизм бухгалтерского учета применим для распределения прибыли?

В контексте возникновения вознаграждений работников на основе акций (долевых инструментов), дискуссии, связанные с отражением в учете такого рода операцій, усилились. В первую очередь это обусловлено отсутствием единой методики оценки долевых инструментов, хотя в рамках современной методологией учета обозначено применение концепции справедливой стоимости. Правило оценки по справедливой стоимости установлено IFRS 2 «Выплаты на основе долевых инструментов», регламентирующим порядок признания и отражения в отчетности операций по расчетам с работниками, путем предоставления им вознаграждения на основе долевых инструментов [13]. Необходимо подчеркнуть, что порядок, установленный IFRS 2, относится к вознаграждениям сотрудников, имеющих полномочия и несущих ответственность за планирование, руководство и контроль над деятельностью организации - вознаграждениям за человеческий капитал.

Для разработки механизма учета операций по вознаграждениям на основе акций необходимо решить вопрос их идентификации в качестве элемента финансовой отчетности. На первый взгляд достаточно сложно определить, в каком разделе и какая статья Отчета о финансовом положении (Балансе) будет иметь место изменение: в капитале или в обязательствах. IFRS 2 рекомендует применять следующий подход: если согласно договорному соглашению организация выпускает фиксированное число собственных долевых инструментов (обыкновенных акций) в обмен на услугу, то такой договор является долевым инструментом, если в договоре обозначена обязанность организации выплатить денежные средства, то такой договор идентифицируется в качестве обязательства. При 
этом и долевой инструмент, и обязательство должны оцениваться по справедливой стоимости суммы погашения.

В рамках данной статьи намеренно акцентируется внимание на механизме признания вознаграждений на основе акций в качестве капитала, как результата демонстрации $\beta$-активности работников. Представим в таблице 2 предлагаемый авторами механизм отображения обозначенного рода операций на базе существующих подходов в рамках положений МСФО.

Таблица 2

Модель отражения операций при вознаграждении работников на основе акций*

\begin{tabular}{|c|c|c|c|}
\hline \multirow{2}{*}{$\begin{array}{c}\text { Момент } \\
\text { признания }\end{array}$} & \multirow{2}{*}{ Содержание операции } & \multicolumn{2}{|c|}{ Корреспондирующие счета } \\
\hline & & Дт счетов & Кт счетов \\
\hline \multirow{2}{*}{$\begin{array}{c}\text { Вознаграждения на } \\
\text { основе акций }\end{array}$} & Реинвестирование прибыли & Использованная прибыль & $\begin{array}{c}\text { Эмиссионный доход или } \\
\text { Резервы, предусмотренные } \\
\text { уставом }\end{array}$ \\
\hline & $\begin{array}{c}\text { Признаны расходы по } \\
\text { вознаграждению } \\
\end{array}$ & Финансовые расходы & Использованная прибыль \\
\hline $\begin{array}{c}\text { Дополнительной } \\
\text { эмиссии наделения } \\
\text { правами } \\
\end{array}$ & $\begin{array}{c}\text { Сумма увеличения } \\
\text { акционерного капитала }\end{array}$ & Неоплаченный капитал & Акционерный капитал \\
\hline $\begin{array}{c}\text { Исполнения } \\
\text { наделения правами }\end{array}$ & Закрытие счетов & $\begin{array}{c}\text { Эмиссионный доход или } \\
\text { Резервы, предусмотренные } \\
\text { уставом } \\
\end{array}$ & Неоплаченный капитал \\
\hline
\end{tabular}

*Авторская разработка

Для отражения в учете такой операции целесообразно открыть отдельный субсчет «Размещение долевых инструментов» либо к счету «Эмиссионный доход», либо к счету «Резервы, предусмотренные уставом» [10, с. 204210]. Расчеты с работниками за $\beta$-активность могут осуществляться по их выбору одной из альтернатив: либо долевыми инструментами, либо денежными средствами, при этом бизнес- единица отражает эмиссию сложного (комбинированного) инструмента. В данной ситуации составитель отчетности должен руководствоваться профессиональным суждением, сформированным на базе знаний как указанного стандарта, так и экономических теорий о сущности капитала и обязательств, которая рассмотрена авторами в работе: [11, c. 150-159].

Таблица 3

Общая схема бухгалтерского учета операций при вознаграждении работников на основе сложных инструментов*

\begin{tabular}{|c|c|c|c|}
\hline \multirow{2}{*}{ Момент признания } & \multirow{2}{*}{ Содержание операции } & \multicolumn{2}{|c|}{ К Корреспондирующие счета } \\
\hline & & Дт счетов & Кт счетов \\
\hline \multirow{2}{*}{$\begin{array}{c}\text { Вознаграждение при } \\
\text { выборе } \\
\text { альтернативы: или } \\
\text { на основе акций или } \\
\text { наличностью }\end{array}$} & $\begin{array}{c}\text { Признаны расходы } \\
\text { отчетного периода по } \\
\text { вознаграждению работника }\end{array}$ & $\begin{array}{l}\text { Текущие расходы } \\
\text { будущих периодов }\end{array}$ & $\begin{array}{c}\text { Обязательства персоналу по } \\
\text { оплате труда }\end{array}$ \\
\hline & $\begin{array}{c}\text { Признан долевой компонент } \\
\text { вознаграждения }\end{array}$ & $\begin{array}{l}\text { Текущие расходы } \\
\text { будущих периодов }\end{array}$ & $\begin{array}{l}\text { Эмиссионный доход/ } \\
\text { Долевой компонент }\end{array}$ \\
\hline \multirow{2}{*}{$\begin{array}{c}\text { Выбор } \\
\text { вознаграждения на } \\
\text { основе акций }\end{array}$} & $\begin{array}{c}\text { Признаны расходы } \\
\text { отчетного периода по } \\
\text { вознаграждению работника }\end{array}$ & Финансовые расходы & $\begin{array}{c}\text { Текущие расходы будущих } \\
\text { периодов }\end{array}$ \\
\hline & $\begin{array}{c}\text { Реклассификация } \\
\text { обязательств }\end{array}$ & $\begin{array}{c}\text { Обязательства персоналу } \\
\text { по оплате труда }\end{array}$ & $\begin{array}{c}\text { Краткосрочные } \\
\text { конвертируемые займы }\end{array}$ \\
\hline \multirow{2}{*}{$\begin{array}{c}\text { Исполнения } \\
\text { наделения правами }\end{array}$} & Реинвестирование прибыли & $\begin{array}{c}\text { Краткосрочные } \\
\text { конвертируемые займы }\end{array}$ & Акционерный капитал \\
\hline & $\begin{array}{c}\text { Алокация сумм по счету } \\
\text { эмиссионного дохода }\end{array}$ & $\begin{array}{l}\text { Эмиссионный доход/ } \\
\text { Долевой компонент }\end{array}$ & $\begin{array}{c}\text { Эмиссионный } \\
\text { доход/Дополнительная } \\
\text { эмиссия }\end{array}$ \\
\hline
\end{tabular}

*Авторская разработка

Приведем профессионального следующий

вариант суждения. Бизнес-единица, осуществляющая вознаграждения на основе договора, в котором содержится условие выбора 
его получения, применяет концепцию хозяйственной единицы, согласно которой капитал трактуется как совокупный капитал, включающий собственный и заемный капитал, поэтому и договор как финансовый инструмент будет включать два компонента: долевой инструмент - в составе капитала, долговой - в составе обязательств.

В отсутствии условия выбора капитал трактуется как собственный (концепция собственности) и вознаграждение на основе долевых инструментов идентифицируется как капитал. Необходимо подчеркнуть, что поскольку анализируются и оцениваются обе альтернативы, то механизм отображения операций на базе сложных договоров отличается от вышепредложенного и требует отдельного раскрытия (табл.3).

Как уже выяснено, оценка вознаграждений на базе акций рассматривается как часть оценки ИП, что предопределяет сложность процесса стоимостного измерения, поскольку реализация проекта нацелена на будущее [4, с. 23]. Практика выработала четыре математических модели оценки ИП: “метод дерева решений”, БлэкаШоулза-Мертона, биноминальная и МонтеКарло. Применение этих моделей и рекомендуется IFRS 2 при решении проблемы надежной оценки вознаграждений на основе долевых инструментов.

Выводы и перспективы дальнейших исследований. В основу понятия «вознаграждения на основе акций» положена их юридическая трактовка и экономическая сущность. Сложность понимания этой категории обусловлена тем фактом, что в инновационной экономике труд как фактор производства стал носить двойственный характер: с одной стороны - это деятельность, требующая выплаты по вознаграждению, a c другой - это право собственности индивидуума, требующее признание в составе капитала. В связи с этим в системе бухгалтерского учета возникает ряд проблем в контексте исполнения требования достоверности финансовой отчетности, для разрешения которых необходимо применение концептуального подхода в трактовке вознаграждений на основе акций. Для этого в рамках первого этапа исследования предложено юридическое обоснование признания указанного рода вознаграждений в качестве капитала путем раскрытия правоотношений между работником $\beta$-активности и бизнес-единицей. На втором этапе в результате изучения концепций менеджмента капитала установлена экономическая трактовка вознаграждения работников на основе акций реинвестированная прибыль в составе собственного капитала. На базе первого и второго этапов исследования, носящего концептуальный характер, предложена модель учета вознаграждений на основе акций, которая верна с точки зрения современной методологии бухгалтерского учета - методологии МСФО. Однако, существует ряд проблем, связанных с вознаграждениями на основе акций, среди которых разработка методики их налогообложения и отражения в учете.

\section{СПИСОК ИСПОЛЬЗОВАННЫХ ИСТОЧНИКОВ}

1. Беккер, Г. Человеческое поведение: экономический подход. Избранные труды по экономической теории: перевод с англ. - М.: ГУ ВШЭ, 2003. - 627 с.

2. Глазл, Ф. Динамичное развитие предприятия. Как предприятия-пионеры и бюрократия могут стать эффективными/Ф., Глазл, Б., Ливехуд/ Пер. с нем. - Калуга: Духовное познание, 2000. - 264 с.

3. Мизес, Л. Человеческая деятельность: трактат по экономической теории/Л. Мизес; пер. с англ. Челябинск: Социум, 2012. - 878 с.

4. Лукашов, А. Метод Монте-Карло для финансовых аналитиков: краткий путеводитель/Управление корпоративными финансами. №1 (19). 2007, с. 22-39

5. Пятов, М. Бухгалтерский учет для принятия решений /м. Пятов. - М.: ООО «1С-Паблишинг», 2009. $268 \mathrm{c}$.

6. Саватье, Р. Теория обязательств: практический и экономический очерк/Р., Саватье./пер. с фр. - Москва: Прогресс, 1972. - 440 с.

7. Сапарова, Б. Финансовый менеджмент. Учебное пособие/Б. Сапарова. -Алматы.: Экономика, 2008. 848 c.

8. Соколов, Я. История бухгалтерского учета/Я., Соколов, В., Соколов. - М: Финансы и статистика, 2004. $272 \mathrm{c}$.

9. Хендрексен, Э., Теория бухгалтерского учета./ Э. Хендрексен, М. ван Бреда. - М.: Финансы и статистика, 1997,576 с.

10. Цуркану, В. Составление финансовой отчетности в соответствии с международными стандартами: Учебно-практическое пособие (на сквозном примере)/ В. Цуркану, И. Голочалова.- Кишинэу: АСАР, 2014,480 c. 
11. Цуркану, В. Проблемы бухгалтерского учета обязательств: эволюция и современное состояние / В. Цуркану, И. Голочалова // Бухгалтерські наукові дослідження в ЖДТУ. - Житомир: ЖДТУ, 2015. - С. 147-177.

12. Legenchuk S., Polishchuk I. Organizational and methodical approaches to disclosure of income distribution in integrated reporting (2017) [Электронный ресурс]. - Режим доступа: https://pbo.ztu.edu.ua/article/view/110476Publication/vwLuAssets-

13. Международные стандарты финансовой отчетности. [Электронный ресурс] - Режим доступа: http://www.mf.gov.md/ru/lex/contabilitate...

\section{REFERENCES}

1. Bekker, G. (2003). Chelovechescoye povedenie: economicheskiy podhod. Izbranye trudy po economicheskoy teoriy [Human behavior: economical approach. Selected works on economic theory]. (Trans.). M.: GU VShE [in Russian].

2. Glazl, F., \& Livehud, B. (2000). Dinamichnoie razvitie predpriyatya. Kak - predpriyatya-pionery i burokratiya mogut stat' effertivnymi [Dinamic development of an enterprise. How could a pioneer branding enterprise be effective]. (Trans.). Kaluga: Duhovnoie poznanie [in Russian].

3. Mises, L. (2012). Chelovecheskaya deyatel'nost': tractat po economicheskoy teoriy [Human action: A treatise on economics]. (Trans.). Cheliyabinsk: Sotsium [in Russian].

4. Lukashov, A. (2007). Metod Monte-Carlo dlya finansovyh analiticov: cratkiy putevoditel' [Monte Carlo
[Mand techiques for financial analysts: brief guide]. Upravlenie corporativnymi finansami - Corporate Finance Management, 1 (19), 22-39 [in Russian].

5. Pyatov, M. (2009). Buhgalterskiy uchet dlya prinyatiya resheniy [Accounting into the decision-making process]. M.: «1S-Publishing» [in Russian].

6. Savat'ie, R. (1972). Teoriya obyazatel'stv: practicheskiy i economicheskiy ocherc [Theory of Obligations: practical and economical essay]. (Trans.). M: Progres [in Russian].

7. Saparova, B. (2008). Finansovyi manegment [Financial Management]. Almaty: Economica [in Russian].

8. Socolov, Ya. (2004). Istoriya buhgalterskogo ucheta [Accounting History]. M: Finansy i statistica [in Russian].

9. Hendrecsen, E. \& Van Breda, M. (1997). Teoriya buhgalterskogo ucheta [Accounting Theory]. (Trans.). M.: Finansy i statistica [in Russian].

10. Tsurcanu, V. \& Golochalova, I. (2014). Sostavlenie finansovoi otchetnosti v sootvetstvii s mezhdunarodnymi standartami [Preparating financial reporting acordance with international standatds]. ACAP, Ch. [in Russian].

11. Tsurcanu, V. \& Golochalova, I. (2015). Problemy buhgalterskogo ucheta obyazatel'stv: evol'utsiya i sovremenoie sostoyanie. [Problems of liabilities accounting: evolution and present status]. Bukhhalters'ki naukovi doslidzhennya v ZHDTU - Accounting scientific research in ZhDTU, 147-177 [in Russian].

12. Legenchuk, S. \& Polishchuk, I. (2017). Organizational and methodical approaches to disclosure of income distribution in integrated reporting. https://pbo.ztu.edu.ua. Retrieved from: https://pbo.ztu.edu.ua/article/view/110476Publication/vwLuAssets- [in English].

13. Mejdunarodnie standarty finansovoy otciotnosti [International Financial Reporting Standards]. (n.d.). http//www.mf.gov.md. Retrieved from: http//www.mf.gov.md/ru/lex/contabilitate.

Одержано 14.03.2018 p. 